\title{
Computational Fluid Dynamics in Aerospace Industry in India
}

\author{
K.P. Singh*, J. S. Mathur**, V. Ashok", and Debasis Chakraborty ${ }^{\dagger}$ \\ * Aeronautical Development Agency, Bengaluru-560 017 \\ ** National Aerospace Laboratories, Bengaluru-560 017 \\ \# Vikram Sarabhai Space Centre, Thiruvananthapuram-695 022 \\ ${ }^{\dagger}$ Defence Research and Development Laboratory, Hyderabad-500 058 \\ E-mail:debasis_cfd@drdl.drdo.in
}

\begin{abstract}
The role of computational fluid dynamics (CFD) in the design of fighter aircraft, transport aircraft, launch vehicle and missiles in India is explained. Indigenous developments of grid generators, 3-D Euler and NavierStokes solvers using state-of-the-art numerical techniques and physical models have been described. Applications of these indigenous softwares for the prediction of various complex aerodynamic flows over a wide range of Mach number, angle of attacks, are presented. Emergence of CFD methods as an efficient tool for aerospace vehicle design is highlighted.
\end{abstract}

Keywords: Computational fluid dynamics, missile aerodynamics, aerospace vehicles design

\section{INTRODUCTION}

With the advent of powerful computers and advanced numerical algorithms, computational fluid dynamics (CFD) has revolutionised the aerodynamic and propulsion design of aerospace vehicles all over the world. In India also, the aircraft, launch vehicle and missile designers are depending heavily on CFD techniques for the accurate prediction of various aerodynamic and propulsion parameters in the design exercise. While experimental testing will always remain an integral part of the design, CFD is reducing the dependencies on experimental testing and has emerged as one of the important design tools for aerospace vehicle design. Maturity of CFD is enabling modelling and simulation of flow over aerospace vehicles with full geometric complexities including various combinations of weapons.

A few review papers ${ }^{1-5}$ appeared in the literature about the status of CFD in various aerospace design activities in India. Significant advances in numerical algorithm and computer architecture and CFD applications have been made by $R \& D$ institutions in India since the first review on status of CFD in India by Prahlad ${ }^{1}$. Dessai ${ }^{2}$ and Chakrabartty ${ }^{3}$ has discussed relative roles of CFD and wind tunnel testing in the development of aircraft and has given an account of application of CFD at National Aerospace Laboratory (NAL) for the development of transport aircraft. Singh ${ }^{4}$ presents the role of CFD in the design of light combat aircraft configuration and the application of CFD technique in aeropropulsive characterisation of missiles is presented by Sinha, et $a l^{5}$. The recent assessment of research work in CFD in India by Shevare ${ }^{6}$ focuses on CFD education and various techno-managerial issues. A comprehensive account of CFD applications in the design and analysis of aerospace vehicles including launch vehicle, fighter aircraft, passenger aircraft, missiles, etc is not available in the current literature. The development of indigenous CFD codes and some recent important applications in the design exercise of various aerospace vehicles in the country is presented.

\section{COMBAT AIRCRAFT DEVELOPMENT PROGRAMME-APPLICATION OF CFD}

Right from the initial design and development phases of light combat aircraft (LCA), the applications of CFD has been at the forefront of numerous activities of aerodynamic design, including: configuration design and modifications, estimation of aerodynamic loads, estimation of stability derivatives, air intake flow analysis, air data corrections for flow measurement sensors, store trajectory analysis, aerodynamic improvement analyses, to name a few. The vast spectra of applications were possible due to the development of indigenous Euler and Navier-Stokes codes based on multi-block structured and unstructured hybrid grids.

The CFD applications during preliminary design phase (PDP) relied on codes based on linear and full potential theories, where the purpose of analysis was to study various configuration options in order to freeze the candidate configuration with the optimal aerodynamic performance. The development phase, after the design freeze, made extensive use of CFD codes of higher fidelity Euler and Navier-Stokes codes. Some of the applications of CFD at Aeronautical Development Agency (ADA), Bangaluru are presented.

Received 15 June 2010, Revised 19 July 2010 


\subsection{Aerodynamic Loads}

Aerodynamic loads on various components of aircraft (Fig. 1) are required for structural design. An Euler code - aircraft multi-block Euler solver $(\mathrm{AMES})^{7}$, developed through sponsored project at IIT, Kharagpur, was used to generate aerodynamic loads on various components of the aircraft such as radome, canopy, fuselage, wings, fins, actuator fairings etc. Figures 2 and 3 show the comparison of static pressure coefficient $(C p)$ obtained with Euler calculations and the experimental data from NAL wind tunnel over the wing for $\mathrm{M}=0.95$ and the angles of attack (AOA) of $4.65^{\circ}$ and $9.416^{\circ}$, respectively. For aerodynamic load generation for the aircraft configuration with stores, a Cartesian grid-based Euler code - PARAS ${ }^{8}$, was used extensively. Loads were generated for various Mach numbers at different angles of attack with various combinations of stores at different stations under wing and fuselage.

\subsection{Air Data Calibration for Flow Measurement Sensors}

Towards providing adequate redundancy, air data system (ADS) of Indian combat aircraft has been configured with five sensors locations on front fuselage to measure total and static pressures and local flow angularity. The sensors include two side-mounted air data probes (SADP), two

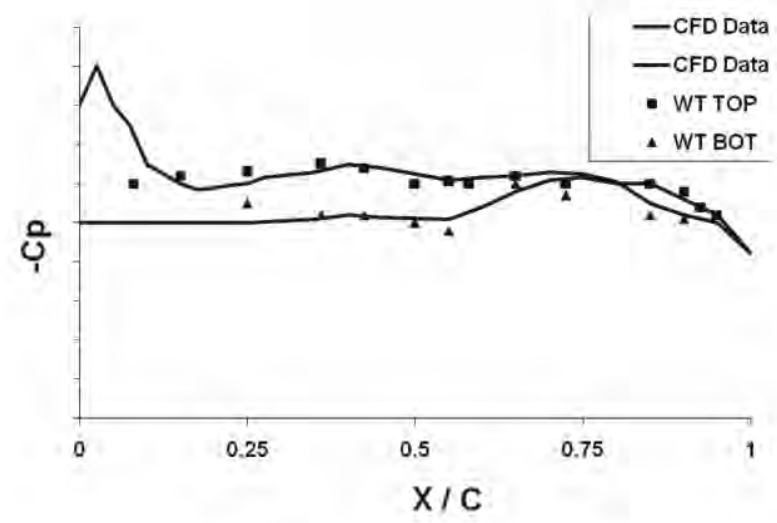

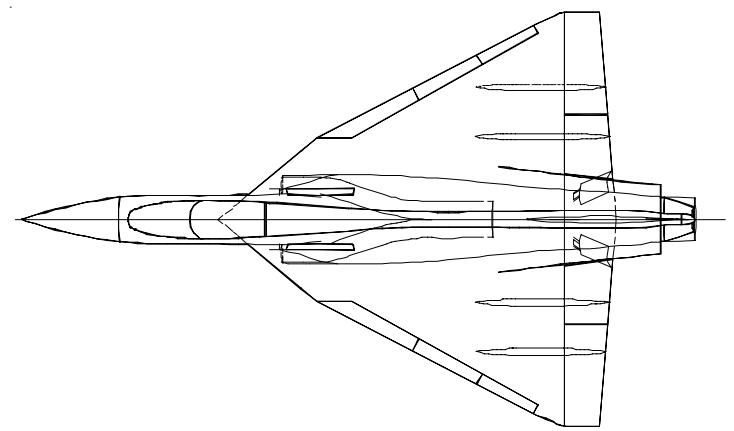

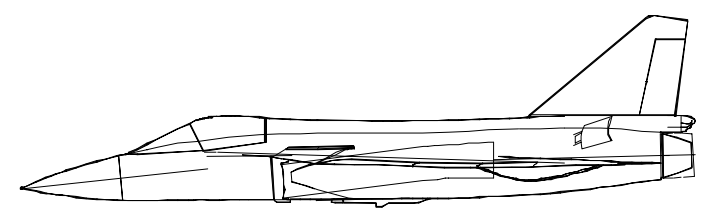

Figure 1. Top and side view of tailless delta aircraft.

angle of attack vanes (AOAV) and one nose air data probe (NADP). The Euler code-AMES was used to generate local flow field (static pressure and flow angularity) data over the aircraft front fuselage. Flow field data thus obtained was used to find a suitable location on the front fuselage for SADP and AOAV at which the local flow field is sensitive

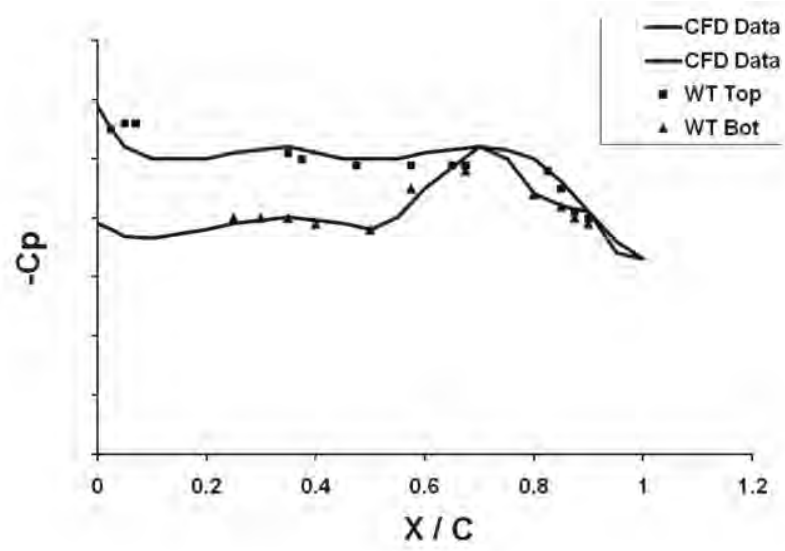

Figure 2. Variation of pressure coefficient $(C p)$ over wing surface at 35 per cent (left) and 48 per cent (right) spanwise stations at $\mathrm{M}=0.95$ and $\mathrm{AOA}=4.65^{\circ}$.
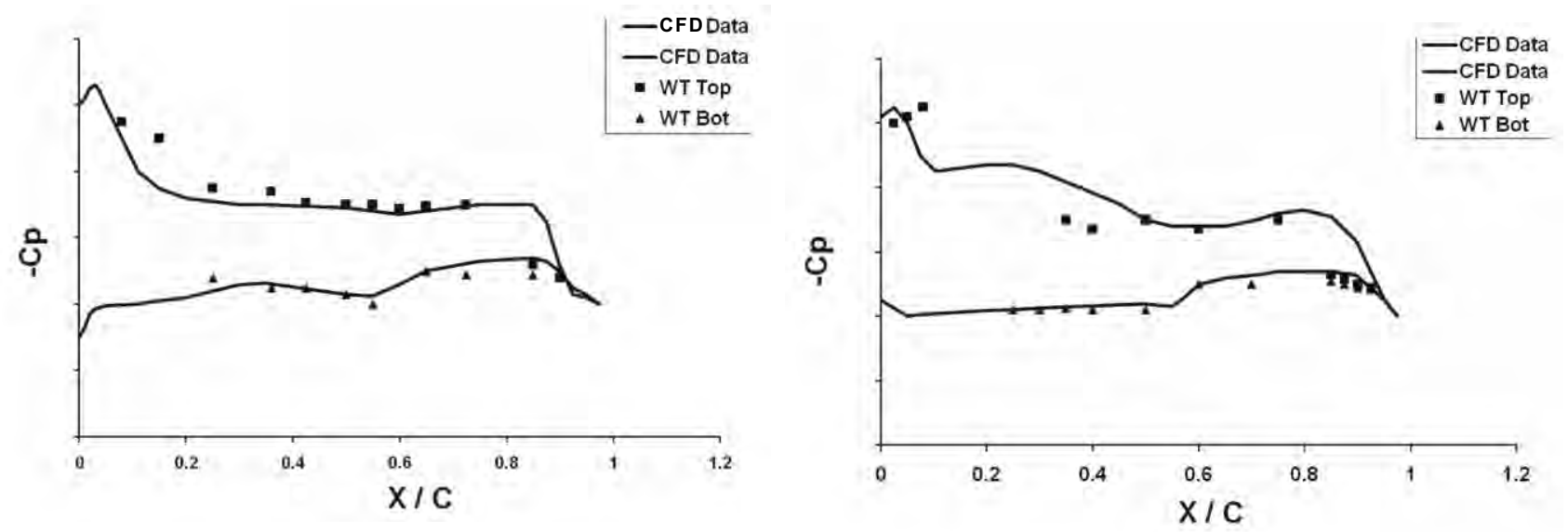

Figure 3. Variation of pressure coefficient $(C p)$ over wing surface at 35 per cent (left) and 48 per cent (right) spanwise stations at $\mathrm{M}=0.95$ and $\mathrm{AOA}=9.416^{\circ}$. 
to the free stream angles of attack and the side slip angles. A comparison of computed data with experimental values at $\mathrm{M}=0.7$ is shown in Fig. 4. Recently, the air data from CFD has been updated with Navier-Stokes calculations with an in-house developed RANS code based on block structured grids CNS3D ${ }^{9}$. Figure 5 shows a comparison of the predicted data at SADP with the data obtained from flight measurements at $\mathrm{M}=0.4$. These validated CFD tools were applied to find the optimal location of air data sensor for new aircraft. Also these tools are applied to assess the effect of front fuselage on nose boom to correct the measured angle of attack, side-slip angles and static pressure.

\subsection{High Angle-of-Attack Flow Simulations}

Viscous computations over the combat aircraft configuration are carried out employing the in-house developed RANS code CNS3D 9 . The computational grid is composed of 1.6 million mesh points. Calculations are performed at a free stream Mach number of 0.7 and different angles of attack. Variation of coefficient of pressure at 35 per cent semi-span stations is compared with the experimental data
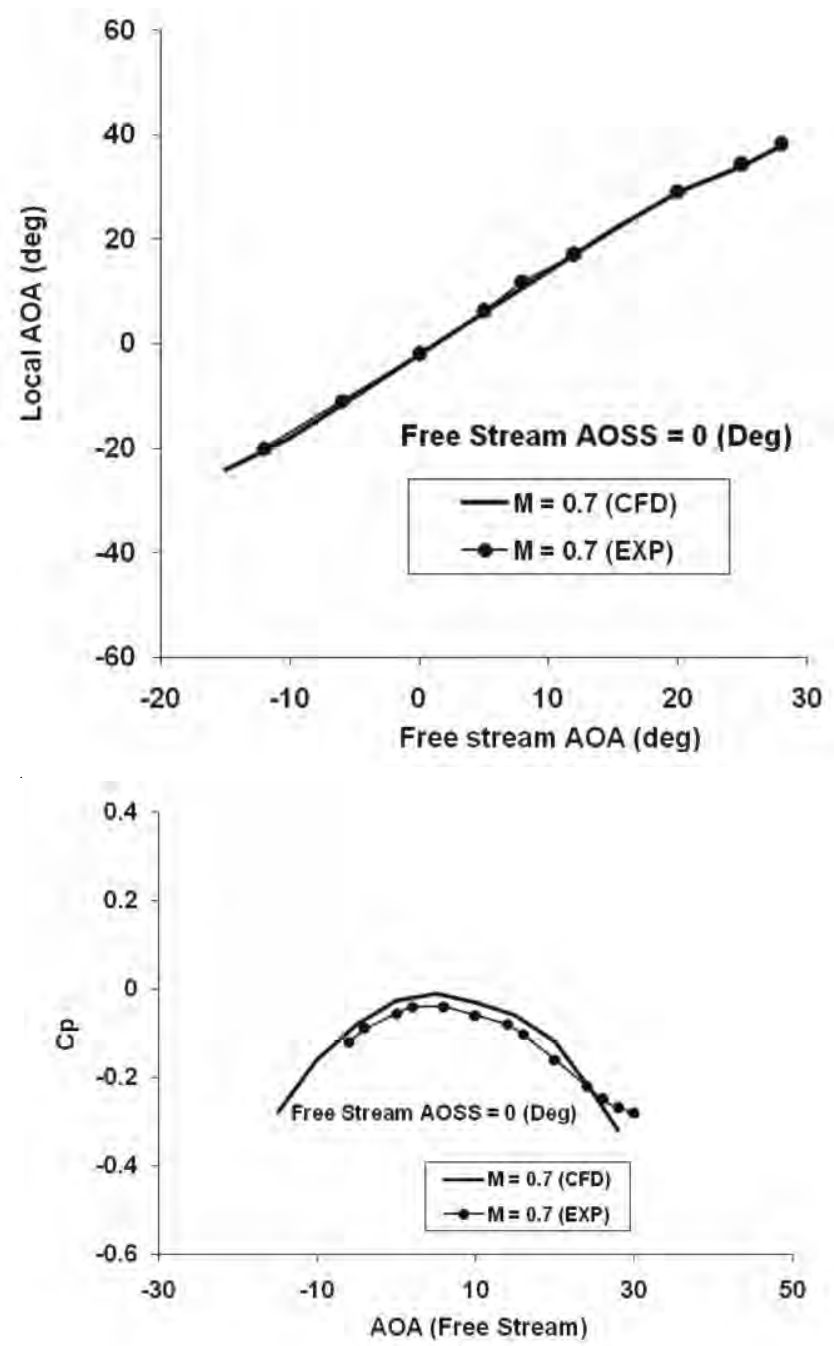

Figure 4. Comparison of CFD with wind tunnel data: local AOA (upper) and Cp (lower) at SADP.
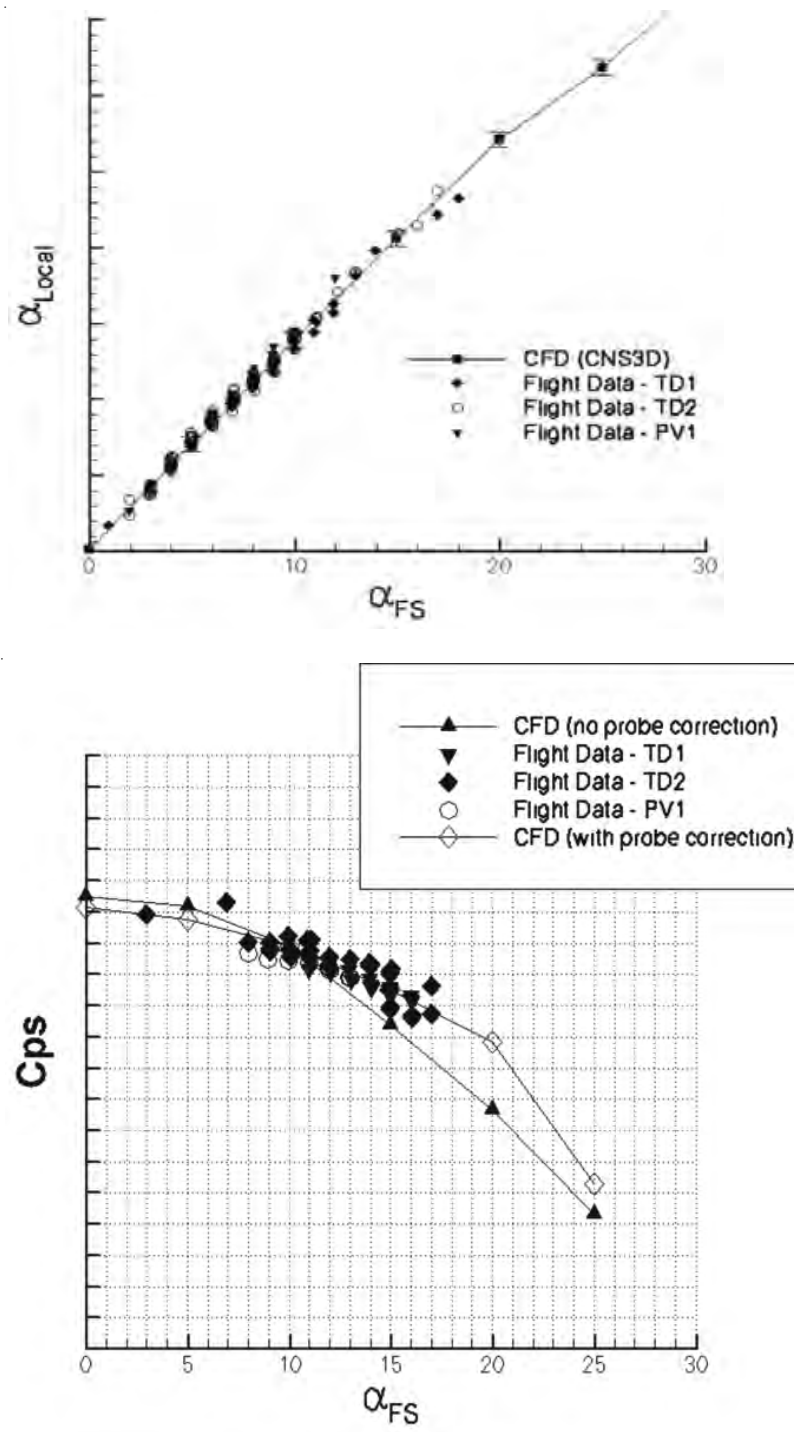

Figure 5. Comparison of CFD with flight data: Local AOA (upper) and $C p$ (lower) at SADP.

in Fig. 6 for angle of attack $\alpha=13^{\circ}$ and $18^{\circ}$. A fairly good comparison is observed. The vortical flow field captured in calculations is presented in Fig. 7. The particle traces illustrate the detailed structure of the rolled-up vortices. It is seen that the leading edge vortices are strengthened as the flow develops progressively away from the leadingedge of the wing.

\subsection{Store Trajectory Analysis}

Accurate prediction of the trajectory of a store released from an aircraft is essential to ensure that the released store even in off-design conditions does not come in contact with the parent aircraft and verify that the released store strikes its target. To define the flight envelope, large number of store trajectory simulations are required to study the effect of individual parameters like flight speed, altitude, angle of incidence, thruster setting, fin size, store carriage location, presence of neighbouring stores, etc. on the carriage and release of store. The techniques should not 

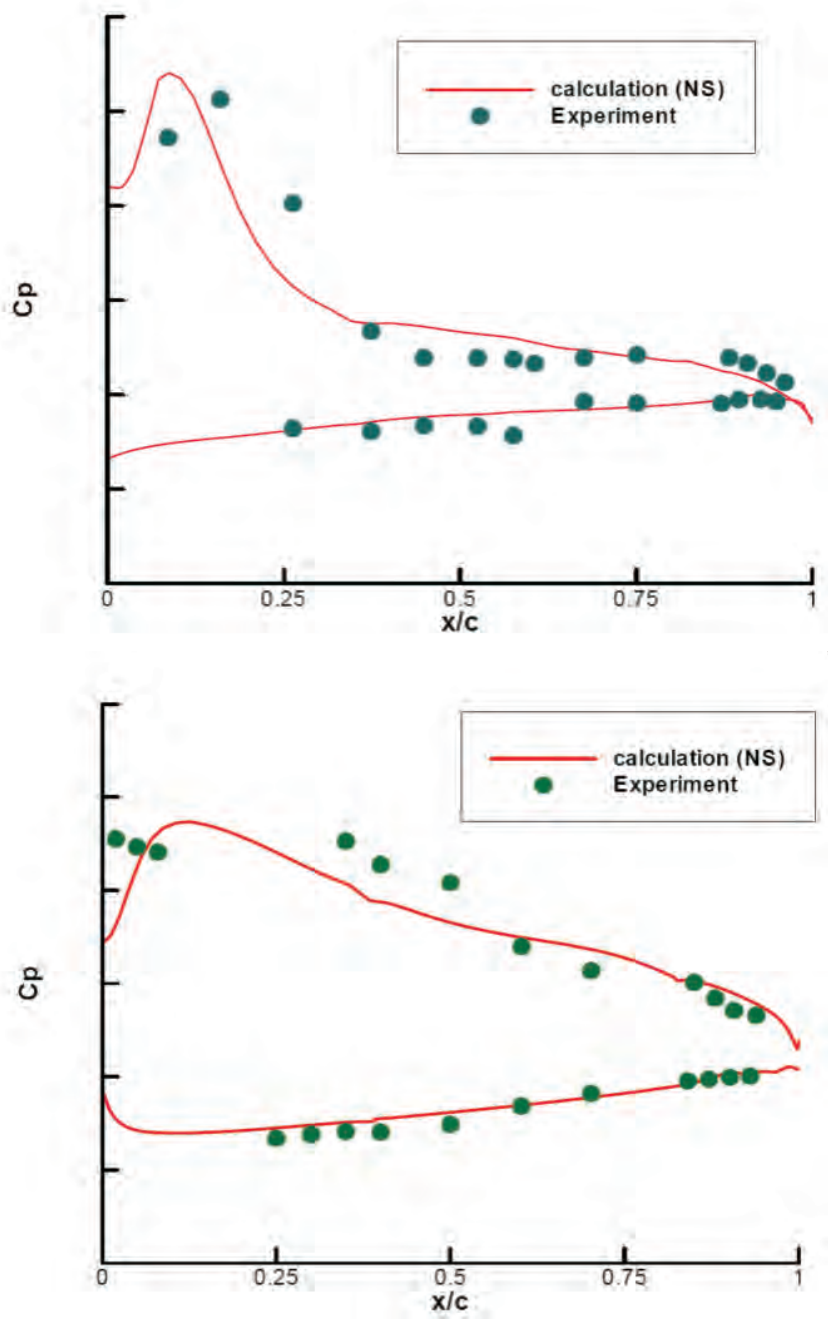

Figure 6. $C p$ variation at 35 per cent semi-span station at $M_{\infty}=0.7$ and $\operatorname{Re}=5.806 \times 10^{6}$ (a), $\alpha=13^{\circ}, \beta=0^{\circ}$ (b) $\alpha=18^{\circ}$, $\beta=\mathbf{0}^{\circ}$.

only provide accurate results with low turnaround time, but also be robust in terms of complexity of configuration and range of flight conditions. ADA has developed a tool for trajectory simulation using online integrated approach. In this approach, the aerodynamic prediction module (Cartesian grid-based Euler code-PARAS, that computes the forces and moments acting on the store) and trajectory evaluation module (a 6-DOF time integration module) is coupled to make an automated program. The current method is capable of simulating store separation without user intervention. The computed store trajectory results are validated against CTS data and found to be in good agreement. Figures 8(a) and 8 (b) compare simulated trajectories of $1000 \mathrm{lb}$ bomb released at $\mathrm{M}=0.5, \alpha=6.0^{\circ}$ against CTS data. While the $\mathrm{y}$ - and $\mathrm{z}$ - states are seen to match well, the $\mathrm{x}$-state from computation shows less movement. The angular states are seen to compare well.

\section{CFD ACTIVITIES AT NATIONAL AEROSPACE LABORATORIES}

CFD activities at the NAL are mostly carried out in
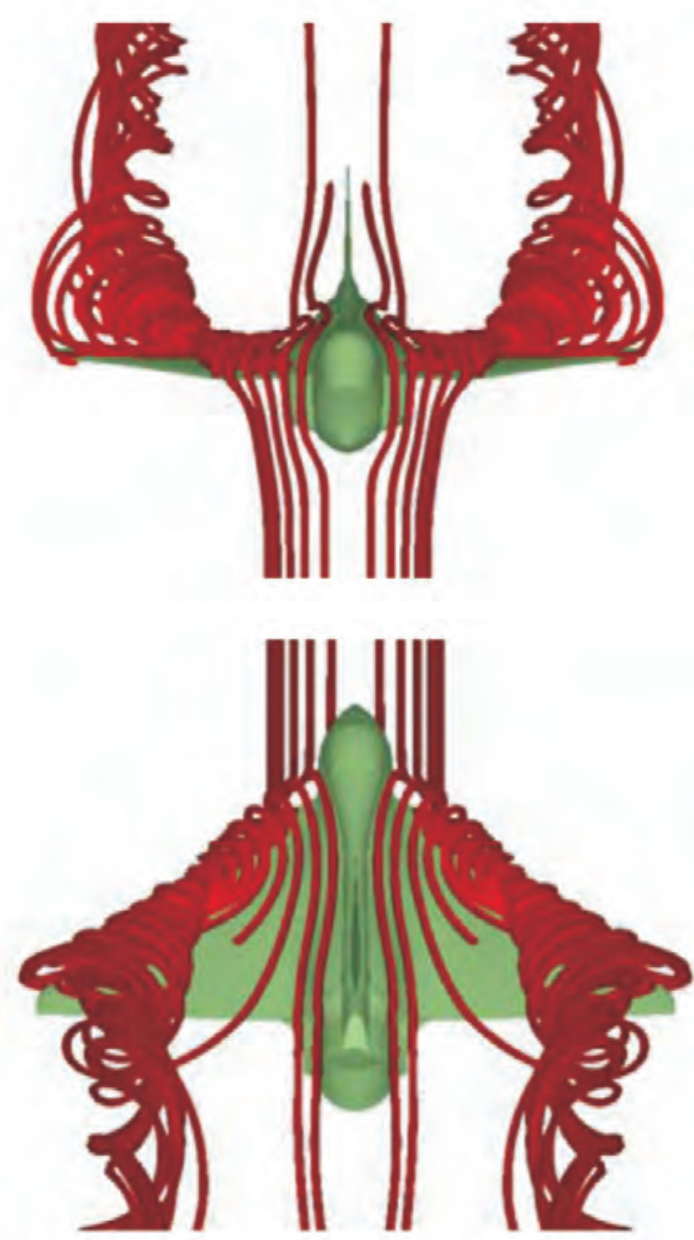

Figure 7. Vertical flow structure at $M_{\infty}=\mathbf{0 . 7}, \alpha=\mathbf{1 8}^{\circ}, \beta=0^{\circ}$, $\operatorname{Re}=\mathbf{5 . 8 0 6} \times 10^{6}$.

computational and theoretical fluid dynamics (CTFD) division which is one of the first CFD groups in the country. Apart from advanced CFD code development activities, the division is also involved in theoretical methods and modelling, software assessment and applications. NAL adopted the route of indigenous development of the CFD solvers rather than using the commercial CFD codes available in the market to have a firm grip on this emerging technology. The development of panel method, grid generation techniques, Euler and Reynolds averaged Navier-Stokes (RANS) codes for different flow regimes, vortex-based methods, algorithmic developments, transition research, turbulence research etc. marked significant milestones. The international cooperation with DLR helped in many ways to realise high-end CFD code development. These developed CFD codes were used extensively to generate the aerodynamic design input for not only NAL initiated civilian aircraft project (HANSA and SARAS) but also for the aerodynamic characterisation of launch vehicle, fighter aircraft and missile programmes of our country. Similarly, activities in these division are extended to hydrodynamics which is of importance to flow around ships and submarines. The CFD code development activities and some applications to various projects are briefly outlined. 

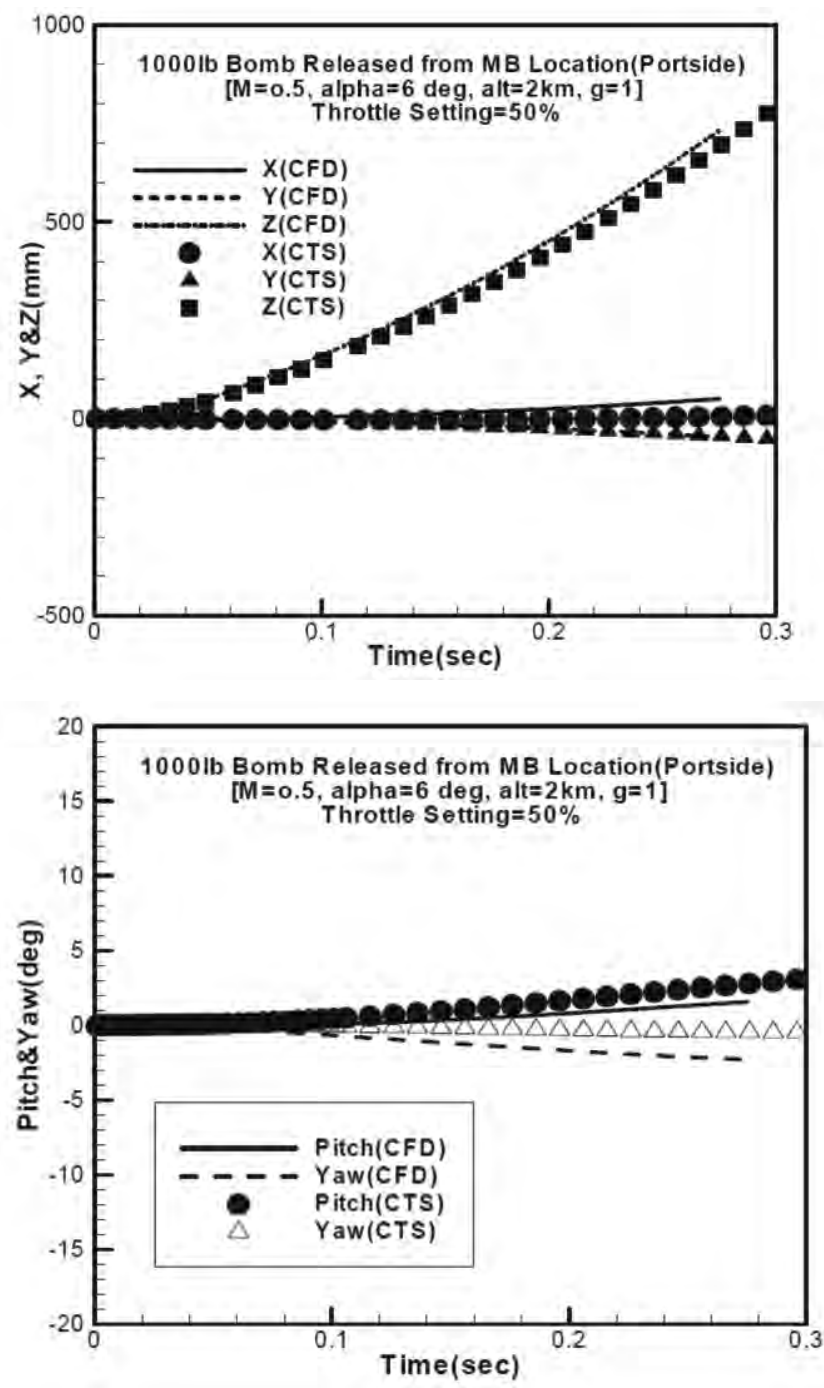

Figure 8. Comparison of $1000 \mathrm{lb}$ bomb trajectory: displacement (upper), angular position (lower).

\subsection{CFD Code Development Activities at NAL}

The panel code is a tool of considerable practical utility in the study of many real-life shapes of concern to aerospace engineers. This software has now been upgraded to make it applicable to rotating bodies such as marine propellers and helicopter rotors, and also to unsteady flows. The code has been used to optimise the wing body junction of NAL developed trainer aircraft HANSA and for aerodynamic characteristics of light transport aircraft SARAS. The development of three-dimensional Euler (JUEL3D) and Navier-Stokes code (JUMBO3D) is presented in a number of publications ${ }^{3,10,11}$. A novel cell vertex finite volume method is employed for the solution of the equation in multi-block structured grid with a five-stage Runge-Kutta scheme to advance the solution on time. Enthalpy damping, implicit residual smoothing, local time stepping, and grid sequencing are used for convergence acceleration. Algebraic eddy viscosity model with correction for separated flow has been used for turbulence closure. The codes are applied to a variety of problems including transonic flow past aerofoils, analysis and design of aerofoil with flap configurations of HANSA, aerodynamic characterisation of complete SARAS aircraft with side slip, characterisation of launch vehicles and fighter aircraft, internal flows through nozzle and cascades etc. Few of the applications of these codes are given in the next subsections. MB-EURANIUM ${ }^{12}$ is another 3-D multi-block RANS code developed in-house with modified Roe scheme. The time integration is performed using either explicit Runge-Kutta method or an implicit LU-SSOR method. Both algebraic Baldwin-Lomax model and the one-equation Spalart-Allmaras are available in the code. This code has been extended for non-equilibrium real gas air chemistry model. The work on the incorporation of transition model in this code is currently under progress. Turbulence research and incompressible flow code development efforts are included in a separate paper in the same issue. The IMPRANS code, developed for unsteady viscous flow computations, has been applied to problems in aeroelasticity ${ }^{13}$. This code solves the unsteady RANS equations using an implicit finite volume scheme on a moving mesh.

\subsection{CFD Applications in Aircraft Design}

\subsubsection{Design of Supercritical and Natural Laminar Flow Aerofoils}

NAL has designed natural laminar flow aerofoils suitable for its civil aircraft projects based on an inverse design procedure. The computed pressure distribution for MSLNF150 aerofoil at $M_{\infty}=0.6$ and at zero angle of attack is shown in Fig. 9. This aerofoil has laminar flow beyond 50 per cent of the chord on both upper and lower surfaces. The supercritical aerofoils designed for transonic flow are very sensitive to small changes in either free stream Mach number or angle of attack. Capturing of double shocks at off-design conditions is a challenging task even for a viscous calculation. The distributions of surface pressure coefficient of a supercritical Korn aerofoil for $\mathrm{M}_{\infty}=0.75$, $\mathrm{Re}_{\infty}=5.42 \times 10^{6}$ at angles of attack ranging from $-0.2^{\circ}$ to $0.9^{\circ}$ are shown in Fig. 10. The first shock near the leading edge moves downstream whereas the second shock remains stationery but its strength decreases with increasing

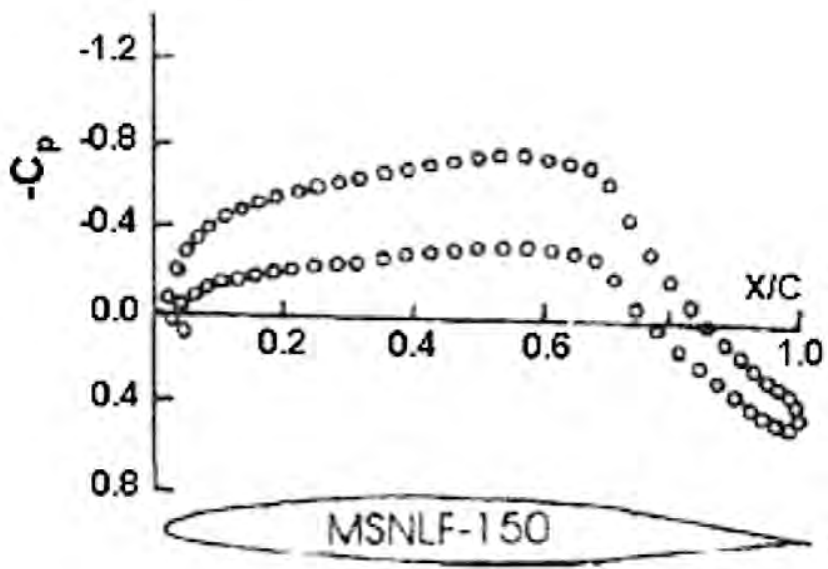

Figure 9. Design of natural laminar aerofoil at NAL $\left(M_{\infty}\right.$ $=0.6, \alpha=0^{\circ}$ ). 


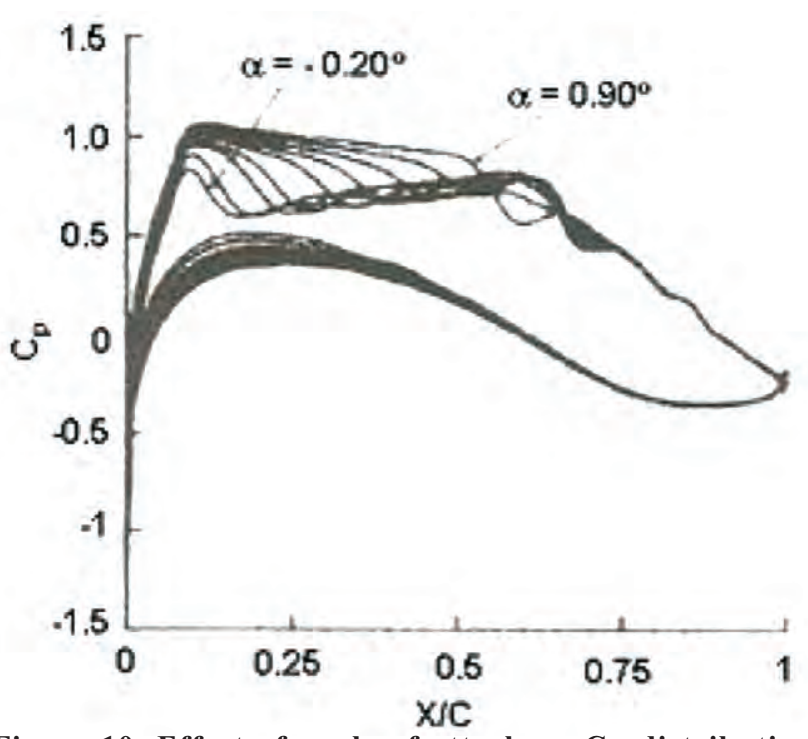

Figure 10. Effect of angle of attack on $\mathrm{Cp}$ distribution at Korn aerofoil for $M_{\infty}=0.75, \operatorname{Re}_{\infty}=5.42 \times 10^{6}$ and $\alpha=$ ranging from $-0.2^{\circ}, 0^{\circ}, 0.25^{\circ}, 0.35^{\circ}$, $0.5^{\circ}, 0.6^{\circ}, 0.7^{\circ}, 0.8^{\circ}$ and $0.9^{\circ}$

angle of attack. At $\alpha=-0.3^{\circ}$ and $-0.4^{\circ}$, a shock-like behaviour was observed near the leading edge but the second shock vanished giving a smooth transition from supersonic to subsonic flow.

\subsubsection{Aerofoil-flap Design of Aircraft}

Effectiveness of control surface is of critical importance for any aircraft. The existing aerofoil flap configuration shows a large separated region which reduced the lift and control effectiveness and the flap are redesigned CFD analysis ${ }^{14}$. A comparison of the existing and modified profiles of the main aerofoil and the flap is shown in Fig. 11. The modified configuration shows almost a linear behaviour in the attached flow region and the maximum $\mathrm{C}_{\mathrm{L}}$ increases with increase in the flap deflection. Comparison of flow pattern between the existing and the modified configurations with streamlines superimposed on pressure contours for
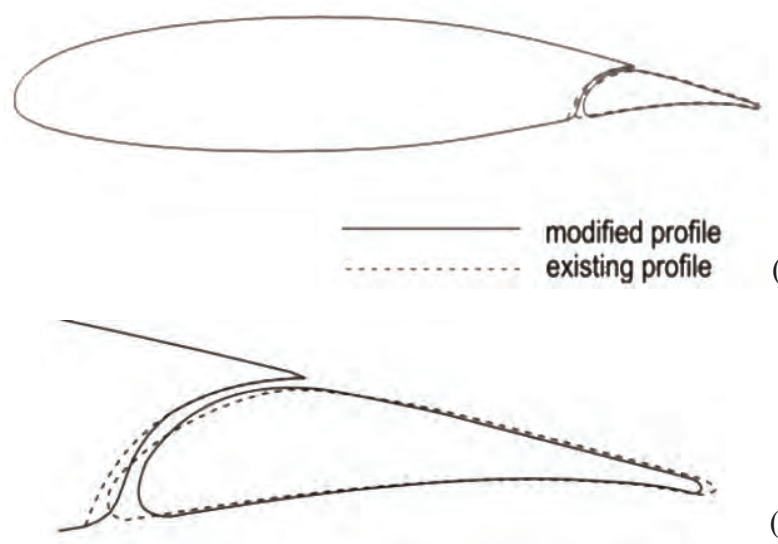

Figure 11. Comparison of existing and modified profiles of aerofoil with flap: (a) complete configuration, and (b) enlarged view near the gap and the flap. $10^{\circ}$ angle of attack and $20^{\circ}$ flap deflection is shown in Fig. 12. The existing configuration exhibits a large portion of separated region over the flap and the modified configuration shows a very smooth behaviour having fully attached flow throughout.
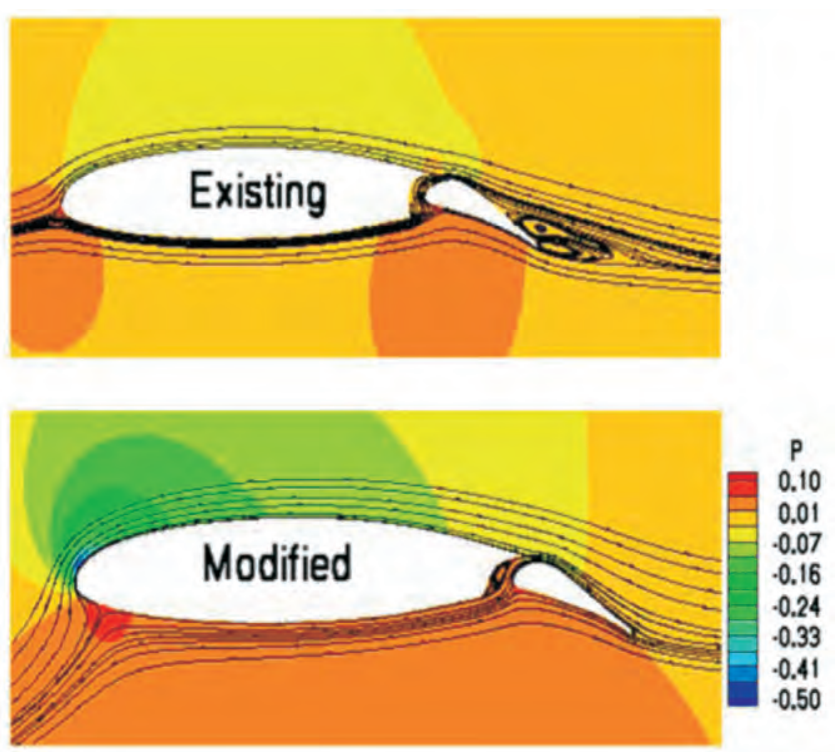

Figure 12. Streamlines and pressure contours of the existing and the modified flap configurations $\left(M_{\infty}=0.3\right.$, $\operatorname{Re}_{\infty}=2 \times 10^{6}, \alpha=10^{\circ}, \delta=20^{\circ}$ )

\subsubsection{Wing-fuselage Fairing Modification for SARAS}

Iterative process is essential for the design of wingfuselage junction for a smooth flow over the surface to obtain minimum mutual interference between the wing and the fuselage. The process involves modifying the contours of fuselage cross-section, generating wing-fuselage intersection curve, and attaching the wing before the flow is analysed and the surface flow pattern is viewed. The wing-fuselage fairing of SARAS is modified through numerical simulation ${ }^{11}$ using JUEL3D code. The original and the modified shapes of a typical cross-section of fuselage after wing was added is shown in Fig. 13. After modification, the wing-fuselage configuration was analysed and the streamlines are shown in Fig. 14 along with those obtained for the original one. The streamline pattern shows that the modified configuration has a smoother flow pattern and does not have the clustering of streamlines on the rear fuselage, as seen in the original one.

\subsubsection{Intake Aerodynamics of Hypersonic Research Vehicle}

The intake is a very critical component of hypersonic airbreathing technology and needs to be highly efficient in terms of pressure recovery and mass capture capability. The flow compression of any hypersonic vehicle starts from forebody and any intake analysis requires simultaneous simulation of external and internal flows. 3-D viscous computations ${ }^{15}$ of the forebody and intake of a hypersonic research vehicle was carried out using an in-house developed RANS code MB-EURANIUM ${ }^{12}$ with Spalart-Allmaras 

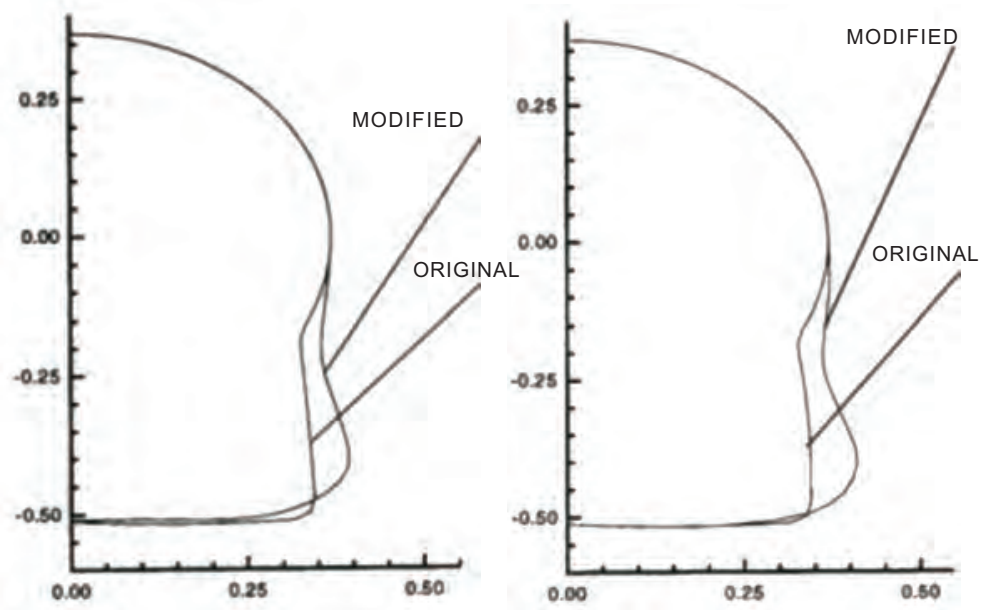

Figure 13.Typical fuselage cross-sections of SARAS showing original and modified fuselages.

turbulence model. The static pressure contours at different axial locations in the forebody including the intake entrance plane, are shown in Fig. 15. Detailed numerical flow visualisation helps to judge the quality of the captured flow. Mass flow rates and pressure recovery obtained at the entrance of three intake ducts (with different heights) were compared and the best intake candidate was identified. The boundary layers developed along the forebody enter the duct and adversely affect the intake performance.

\section{CFD IN LAUNCH VEHICLE DESIGN}

The launch vehicle community has derived immense benefit from CFD for the design and analysis of various launch vehicles. CFD is applied in VSSC mainly for external flows related to aerodynamics and internal flows related to propulsion.

\subsection{Aerodynamic Characterisation Through CFD}

The 3-D NS CFD codes like PARAS-3D, UNS-3D are used extensively in aerodynamic design of launch vehicles. The PARAS-3D code ${ }^{8}$ is a general purpose software which generates automated rectangular adaptive Cartesian mesh for any arbitrary three-dimensional bodies from CAD inputs. The solver is multi-threaded and runs on multiple machines with very good parallel efficiency. The code is also made capable to run in GPU machines. The solver is second order accurate in space with fully explicit scheme using a local time stepping. The inviscid fluxes are computed by means of an approximate Riemann solver and the viscous fluxes by standard central differencing. The limiter of the Min-Mod type is used to limit the gradients during reconstruction. The solver also has capability to handle problems with finite rate chemical reactions. The UNS3D $\operatorname{code}^{16}$ uses a structured grid with a semi-implicit scheme. Flux vector splitting is used for computation of inviscid fluxes. Apart from generating aerodynamic characteristics of different launch vehicles, CFD methods are applied in many important flow problems including refining wind tunnel data for flight condition, estimating heat flux for

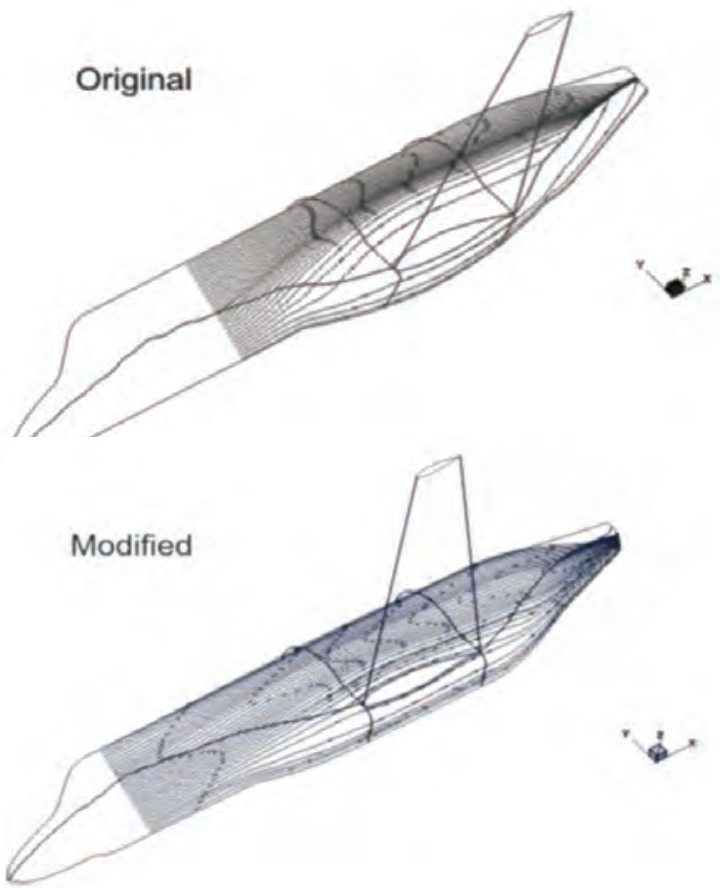

Figure 14. Surface flow patterns on original and modified SARAS wing-fuselage fairing.

wing-elevon gap of a reusable launch vehicle, Estimating starting characteristics of an air intake, studying the effect of entry pressure, flow non-uniformity and vitiation on scramjet combustor performance, etc. Following are some of the typical launch vehicle problems where the CFD has played a major role.

\subsubsection{CFD Studies of Wing-Elevon Gap Heating of a Reusable Launch Vehicle}

The pitch and roll control of reusable launch vehicle is done by deflecting the elevon and there is a $3 \mathrm{~mm}$ gap between the wing and the elevon. To know the flow field in this gap region and to estimate heat flux in this region

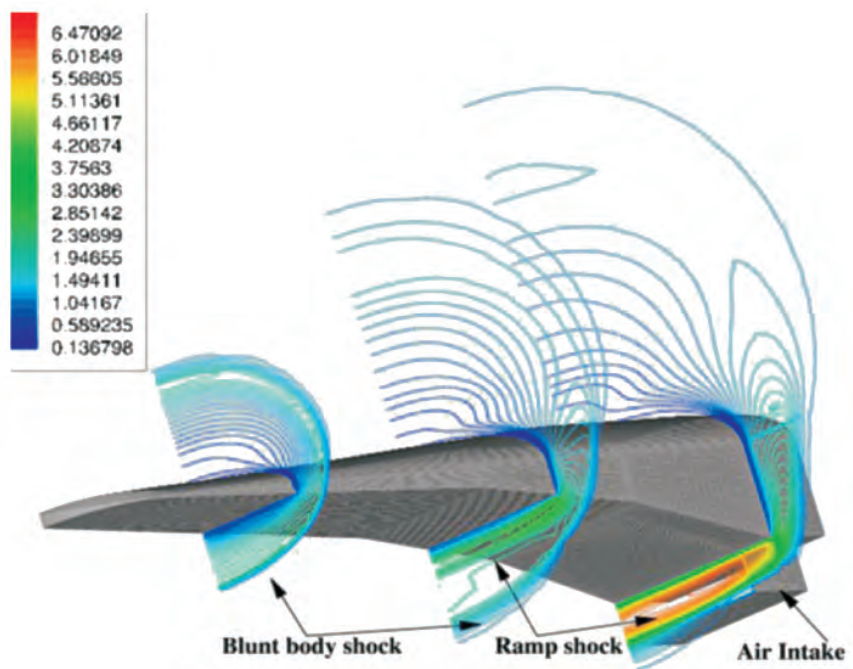

Figure 15. Static pressure contours at different axial locations in the forebody. 
for thermal design detailed CFD simulations ${ }^{17}$ were carried out for two different gaps between the wing and the elevon and also by blocking the gaps using thermal seal. The comparison of the computed heat flux in the wing elevon gap on the elevon leading edge for $3 \mathrm{~mm}$ and $10 \mathrm{~mm}$ gaps (presented in Fig. 16(a)) reveals that the elevon leading edge stagnation heat flux value reduces with reduction of gap from $10 \mathrm{~mm}$ to $3 \mathrm{~mm}$.A big drop in stagnation heat flux value was observed on the elevon leading edge with the thermal seal (presented in Fig. 16(b)).

\subsubsection{CFD Simulations of Starting Characteristics of Hypersonic Air intake}

The intake-starting problem is one of the most important problems associated with intake aerodynamics. The presence of strut inside the combustion chamber reduces the flow passage and creates a throat by choking the flow corresponding to certain upstream conditions. This results in the formation of normal shock ahead of intake, which reduces pressure recovery and mass flow rate. This condition is referred to as the unstarting of the intake. Detailed numerical investigations ${ }^{18}$ were carried out with PARAS3D code to establish the starting and unstarting characteristics of the air intake with different blockages caused by the fuel injection strut. Pressure contours at different longitudinal planes presented in Fig. 17 clearly shows that for 20 per cent blockage, the intake is in started condition with supersonic flow established in the intake; while for 30 per cent blockage, a normal shock is anchored just ahead of the cowl, implying intake un-start. Computed surface pressure matches extremely well with the experimental results, as shown in Fig. 18.

\subsection{CFD in Launch Vehicle Propulsion System Design}

At VSSC, CFD has made significant contributions in the design of solid, liquid, and cryogenic propulsion systems. Reacting and nonreacting flow fields of different complex problems were simulated using indigenously developed finite element-based, two-phase turbulent reacting flow
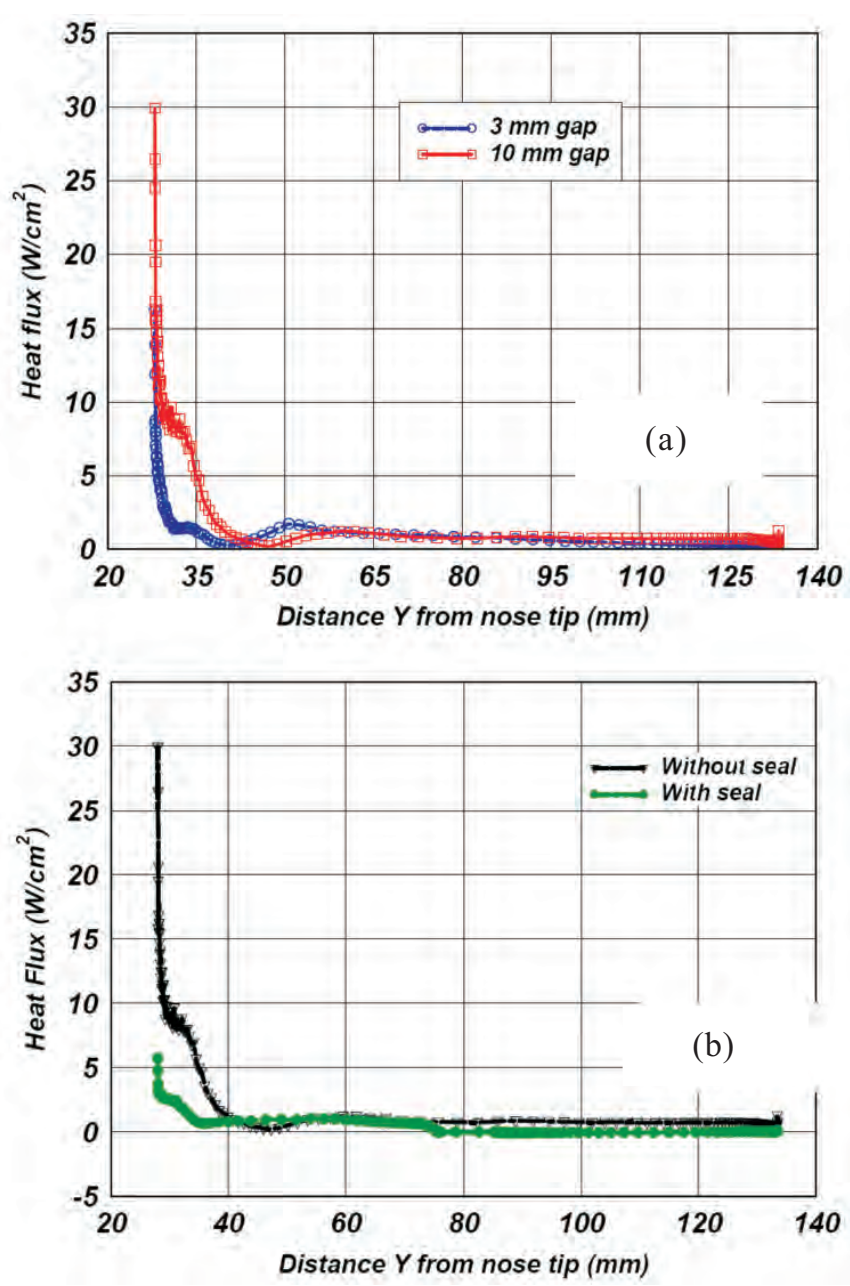

Figure 16. Heat flux distribution comparison in the gap on the elevon side of wing-elevon of reusable launch vehicle: (a) effect of gap, and (b) effect of thermal seal.

code FEXKER2P ${ }^{19}$. Unstructured grid scheme based on finite element method was selected to handle complicated geometry. The code used a Galerkin-Runge-Kutta scheme.
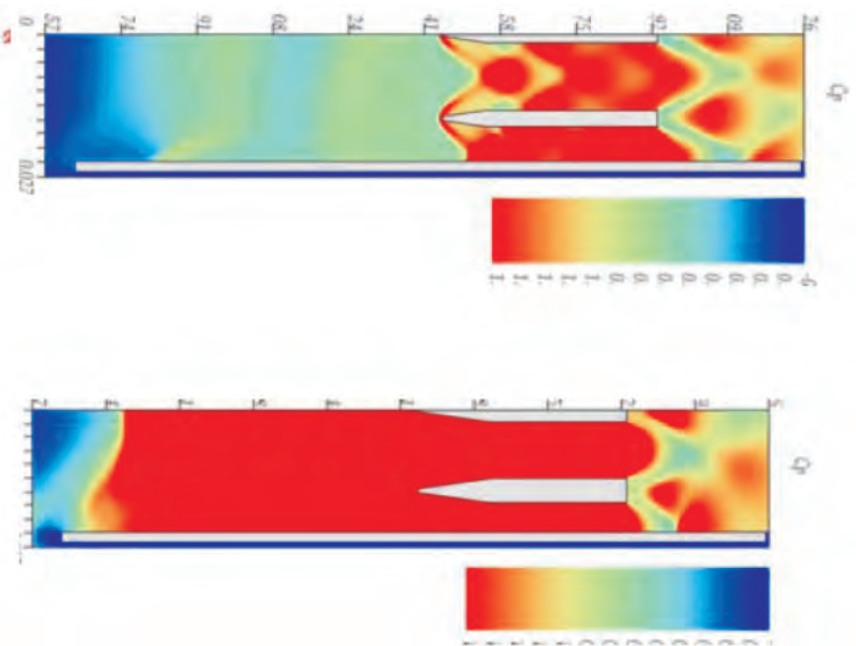

Figure 17. Pressure contours at different planes $(\mathrm{Z}=\mathbf{0} \& \mathrm{Y}=\mathbf{0 . 0 5 6 2})$ : (a) 20 per cent blockage, (b) 30 per cent blockage. 


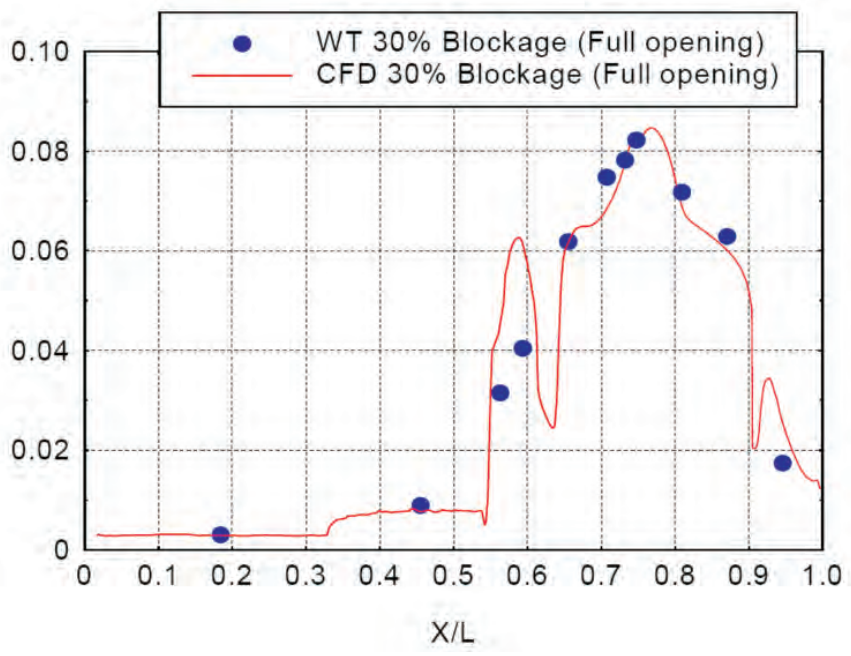

Figure 18. Comparison of computational and experimental surface pressures for 30 per cent blockage.

K- $\varepsilon$ turbulence with low Reynolds number correction and infinitely fast kinetics-based Eddy break up (EBU) and Eddy dissipation concept (EDC)-based combustion models were used. Two-phase coupling between the gas and the particle phase was done through the momentum exchange due to aerodynamic drag and energy exchange due to heat transfer at the interface. An unstructured finite volume method was also developed which used the same finite element grid with a grid converter. Two-step finite rate chemistry scheme involving $\mathrm{H}_{2}, \mathrm{O}_{2}, \mathrm{OH}$ and $\mathrm{H}_{2} \mathrm{O}$ due to Rogers and Chinitz and a generalised $\mathrm{C}-\mathrm{H}-\mathrm{O}-\mathrm{N}$ system for hydrocarbon chemistry with kerosene, $\mathrm{CO}$ and $\mathrm{CO}_{2}$ was incorporated in the code. Integrated performance parameters like thrust and specific impulses were predicted with 1 per cent accuracy. Wall parameters like pressure, heat flux, and shear stress distribution were predicted accurately for optimum structural and thermal design. Various loss mechanisms (divergence loss, viscous loss, two-phase loss, and kinetic loss) were estimated and carefully tuned to a minimum to arrive at a better design of rocket motor. Simulation of cryogenic upper-stage engine and steering engine flow field, supersonic film cooling in cryogenic engine, flow field analysis of solid rocket motor, analysis of liquid hydrogen turbine inlet manifold etc. are some of the notable application of the code in propulsion system design. Some of these applications are presented in detail in the following subsections.

\subsubsection{Simulation of Supersonic Film Cooling in Cryogenic Engines}

The thermal protection of the hardware in liquid and cryogenic engines is accomplished through regenerative cooling and film cooling. The film cooling is complex phenomenon as the coolant directly takes part in the combustion process while protecting the hardware. Some rocket engines expand the turbine exhaust gases at supersonic speed and inject the gases directly at the divergent portion through smaller nozzles positioned outside the main engine.
The location, injection pressure and the angle of injection are to be optimised in such a way that the thrust losses are minimum and cooling is sufficient to keep the hardware in the operating temperature limit. After validating the methodology for Vulcain MK II engine data, simulation were carried out for indigenous cryogenic rocket flow field. The computed Mach number distribution and comparison of computed and experimental wall heat flux are shown in Figs. 19 (a) and (b), respectively. All the flow features were captured and the computed heat flux values match the experimental values reasonably well. One major issue in cryogenic engine simulations is the accurate modelling of near-injector phenomena like swirl, atomisation, vapourisation and mixing. Unless these effects are modelled properly, a complex reaction scheme will not give accurate results.

\subsubsection{Analysis of Liquid Hydrogen Turbine Inlet Manifold}

To find out flow asymmetry in the torroid of the liquid hydrogen manifold, three different numerical simulations namely (i) Flow field simulation in the integrated system, (ii) simulation inside the gas duct with exit conditions matching the torroid pressure, and (iii) simulation without gas duct. It was observed from the integrated simulation that one side of the torroid was getting more mass flow compared to the other side. It was found that bent pipe
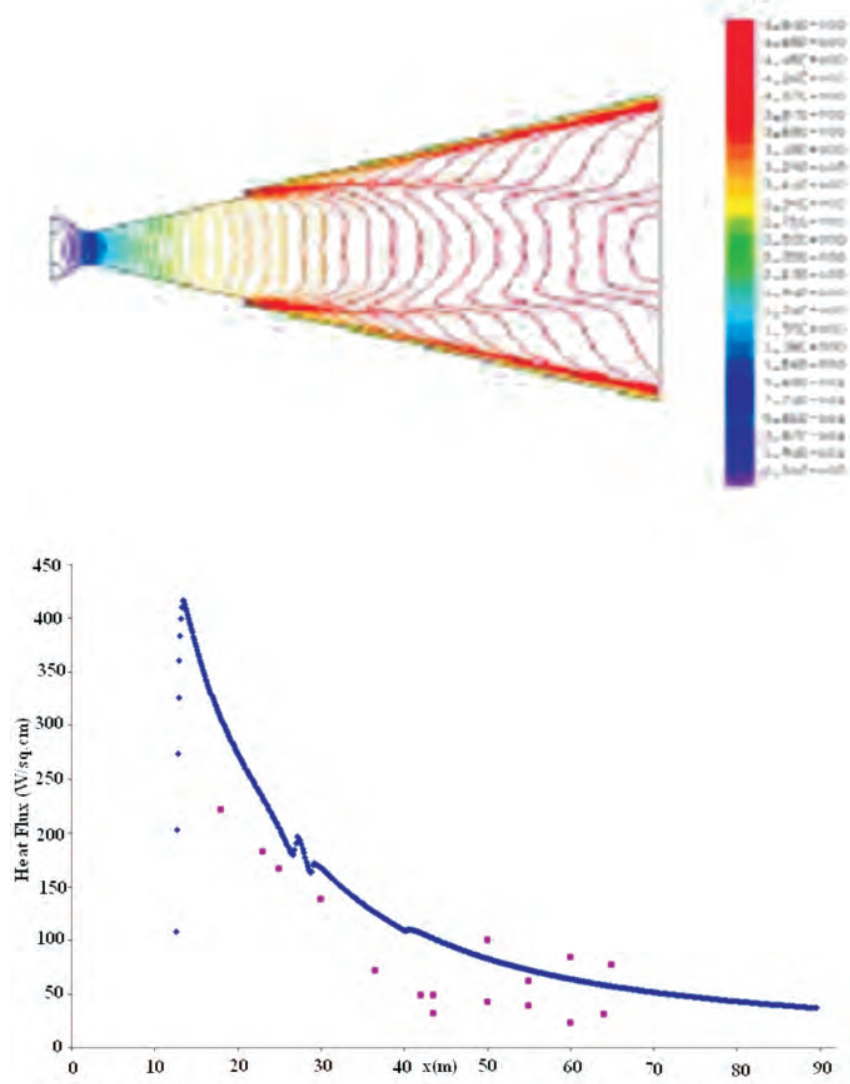

Figure 19. Cryogenic flow field with supersonic film cooling: (a) Mach number distribution (b) Comparison of computed and experimental heat flux. 
creates flow asymmetry in the system and blade alignment did not affect the flow. The Mach number distribution in the integrated system and the torroid are shown in Fig. 20 .

\subsubsection{Flow Field Analysis of Solid Rocket Motor}

Turbulent non-reacting two-phase flow analysis was carried out for solid rocket motor flow field to predict the delivered specific impulse for aluminised propellant. The methodology was validated against AGRAD upper stage test motor result and applied to predict the flow field of solid rocket motor. Flow behaviours including jetting effect at different locations were estimated. It was found that uneven throat erosion was due to canting and jetting effects and the throat was shifted towards the divergent. Velocity profile and maximum velocity inside submerged cavity of a flexed solid rocket motor were estimated. Flexing caused significant changes in the cross-sectional area and reasonably strong circumferential flow was seen to exist within the submerged cavity and that caused significant non-uniform thermal loads on the hardware. Typical Mach number distribution in the solid rocket motor is shown in Fig. 21.

\section{CFD IN MISSILE DESIGN}

DRDL has developed indigenous grid generators and industry standard 3-D Euler and Navier-stokes solver for
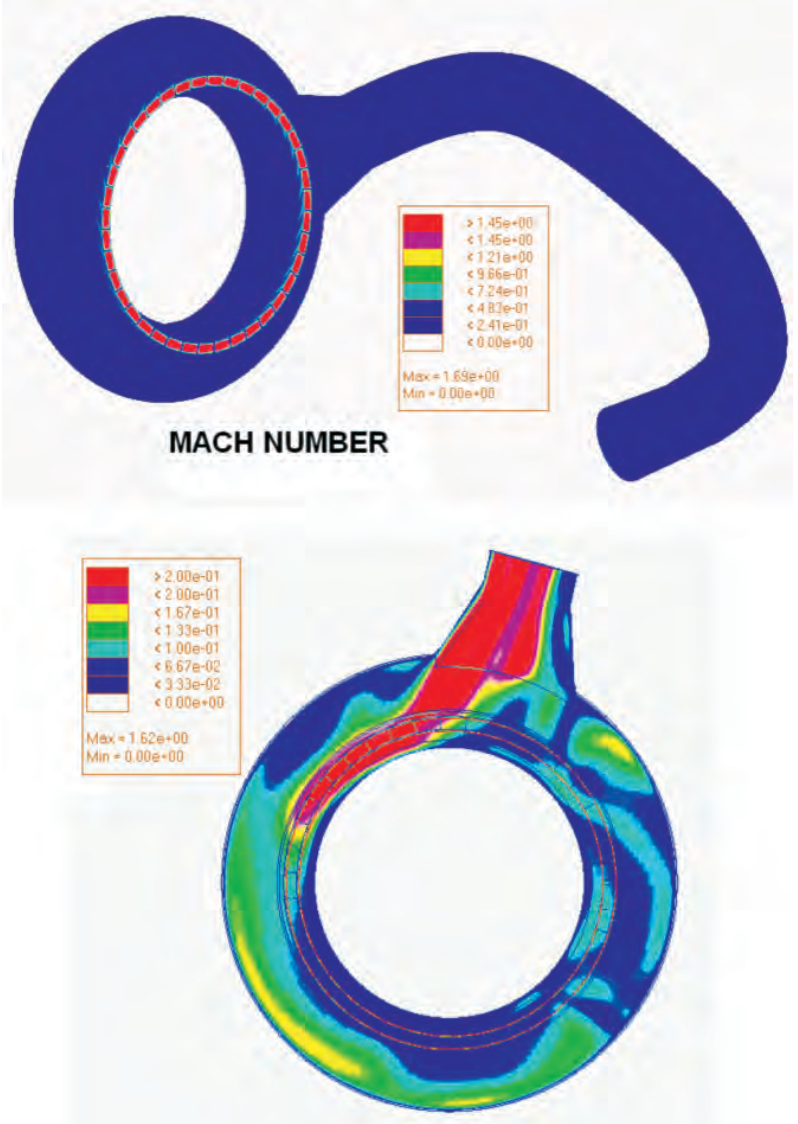

Figure 20. Mach number distribution in: (a) integrated turbine inlet manifold, and (b) torroid. the prediction of complex aerodynamic flows. Systematic validations were carried out through comparisons against reliable experimental results before applying these in the design exercises. Propulsion systems of various ongoing and future missile projects have been designed and analysed using commercial softwares. At DRDL, CFD activities have been presented ${ }^{5}$. Some important developments and applications are presented in this paper.

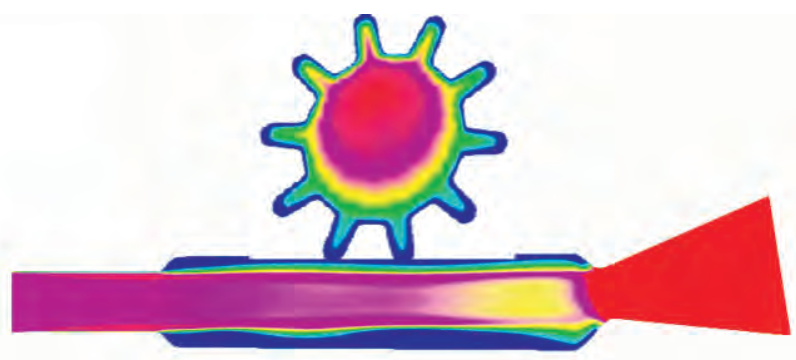

Figure 21.Mach number distributions in a solid rocket motor.

\subsection{CFD Code Development Activities}

A full 3-D elliptic grid generator AUTOELGRID ${ }^{20}$ has been indigenously developed to generate body-fitted structured volume grid for missiles developed by DRDO. The grid generator is highly automated and is being used routinely for generating high quality grids around the missile configuration. A 3-D upwind finite volume Euler solver $\mathrm{KFSG}^{21}$ based on kinetic flux vector splitting (KFVS) was developed and used extensively for aerodynamics characterisation of a number of DRDO missiles and projectiles. For aeroelastic analysis, an unsteady Euler solver (KFMG) is developed in moving grid and was integrated with 2 DOF structural dynamics model. Spring analogy and transfinite interpolation method were employed for grid movement due to deflection and deformation of the oscillating body. The development of industry standard grid-free Euler and Navier-Stokes solver at DRDL and their applications in missile geometries is presented in a paper in the same volume. DRDL has developed a general purpose 3-D RANS solver CERANS ${ }^{22}$ in cell-centered finite volume framework on sequential and parallel computers. The convective fluxes were modelled using several state-of-the-art numerical flux formulae including the KFVS and van Leer flux vector splitting schemes, AUSM family, Roe family, modified Stegerwarming and HLL family of schemes. One-equation SpalartAllmaras turbulence model and SST turbulence model were used for turbulence closure. This code is routinely used at DRDL for simulation of complex high speed flows.

\subsection{Application of CFD Methods for Aerodynamic Characterisation}

The indigenously developed CFD codes are routinely used at DRDL to predict various aerodynamic parameters pertaining to DRDO developed missile systems. Characterisation of missiles in complete $\mathrm{M}-\alpha$ flight regime, control surface 
deflection studies, heat shield separation of hypersonic air-breathing missiles, store separation from the aircraft, study of plume impingement on jet deflector, low-speed (incompressible limit) characterisation of vehicles, aerodynamic heating analysis, etc. are some of the notable applications of the codes. Few important results are presented in the next subsections.

\subsubsection{Simulation of Missile Aerodynamics at High Angle of Attack}

Aerodynamic forces and moments of the different DRDO developed missiles are estimated in complete M$-\delta$ carpet over wide range of Reynolds numbers and very good match is obtained with limited wind tunnel results. To understand the flow physics of severe rolling moment observed in the wind tunnel test at high angle of attack for a low-aspect ratio air-to-air missile, simulations were carried out for free stream Mach number 2.0, angle of attack $20^{\circ}$ and roll angle of $22.5^{\circ}$ using 3-D RANS solver (CERANS) with Spalart-Almaras turbulent model. The total pressure loss contours at various axial locations are presented in Fig. 22. These contours indicate the development of vortices and their interaction with the wing and fin tip vortices. It was observed that due to high angle of attack, the cross flow symmetric vortices emanating from the body were split by the wing asymmetrically and these vortices of different strength, coalesce with wing tip vortices of different strength resulting in severe rolling moments.

\subsubsection{Simulation of Stage Jettisoning Flow Field}

Firing of upper stage motor in the close proximity of the spent stage can create lot of disturbances to the upper stage and the event is mission-critical. Numerical simulations were carried out with CERANS code with different separation distances (500 $\mathrm{mm}$ and $1000 \mathrm{~mm}$ ). The Mach number distribution for two different separation distances for free stream Mach 6.0 is compared in Fig. 23. The bow shock ahead of the upper stage nose, a strong shock ahead of the lower stage dome, and the dead-air zone in the cavity region are seen in both the cases. For $500 \mathrm{~mm}$ separation distance, a large recirculation zone in the upper stage cylindrical portion was observed while the flow was relatively clean in the

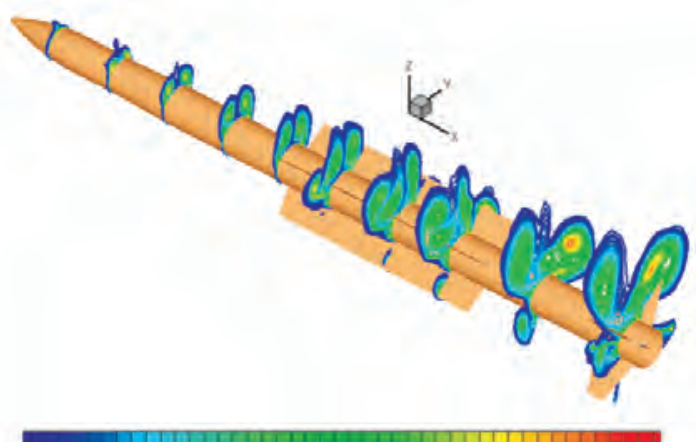

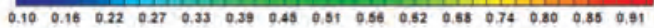

Figure 22. Total pressure loss contours at various axial locations. upper stage for $1000 \mathrm{~mm}$ separation distance. A severe Jet-upstream flow interaction in $500 \mathrm{~mm}$ separation distance case had taken place due to large momentum of flow in the transverse direction which was obstructing the external flow almost at $120^{\circ}$. For $1000 \mathrm{~mm}$ case, the jet was coming out in the external flow zone with lower transverse momentum, making the plume boundary to just graze the tip of upper stage flows. The Mach disc in this case appeared to be different and was dragged in the downstream distance.

\subsubsection{Multidisciplinary Design Optimisation in Aerospace}

Multidisciplinary design optimisation (MDO) paradigms are being increasingly used to design aerospace vehicles that exhibit strong interdisciplinary interactions. To reduce large cycle time in design process, a non-deterministic design methodology, that combines the use of high fidelity analysis (HFA) tools like CFD with reduced order models, has been developed to achieve a robust design ${ }^{23}$. The reduced order models were used to scan the entire design space and the performance was mapped. The developed cumulative distribution function (CDF) of the design space was sequentially sampled to identify a design point wherein the design performance was likely to be better compared to other points and CFD simulation is performed at these selected design points. At the end of the sampling process, a CFD database is aggregated based on which an uncertainty

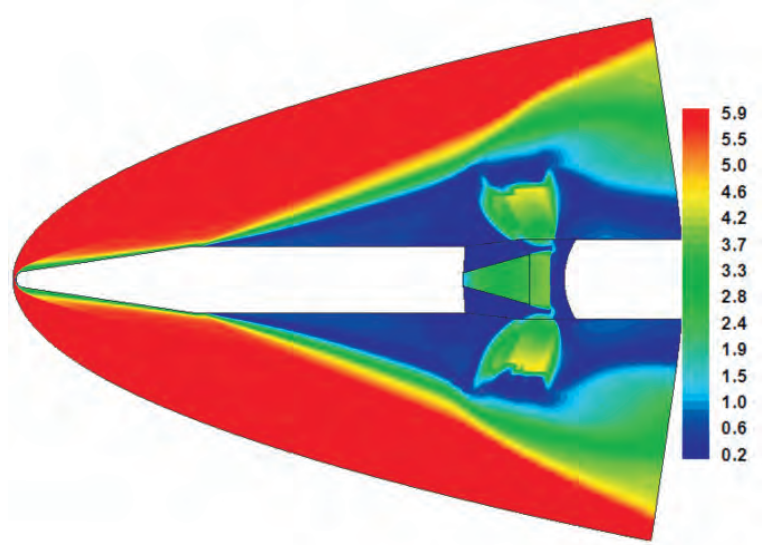

(a)

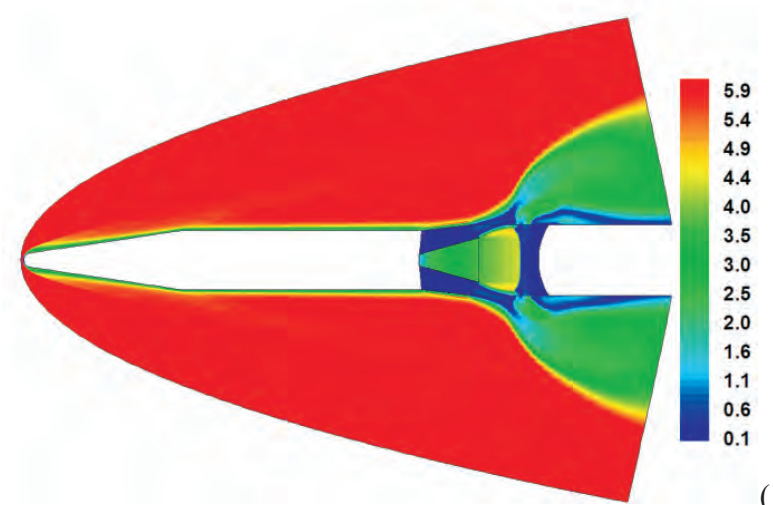

(b)

Figure 23. Mach number distribution with different separation distance: (a) $500 \mathrm{~mm}$ (b) $1000 \mathrm{~mm}$. 
model for the reduced order model was constructed. The reduced order model is combined with the uncertainty model in an optimization-based design framework to enable robust design decisions. Figure 24 compares the entry static pressure $P_{3 \mathrm{~S}}$ of a hypersonic vehicle based on the uncertainty model with the actual CFD results. For low fidelity analysis, the flow is considered as 2-D and the reduced order model to evaluate $P_{3 \mathrm{~S}}$ is based on tangent cone method whereas 3-D CFD analysis using PARAS ${ }^{8}$ represents the HFA tool. Thirteen CFD simulations were used to construct the uncertainty model. In the present case, it is desired to select the design points for CFD simulation such that $P_{3 \mathrm{~S}}$ is relatively high. It can be seen that the predictions bound the true values. Results indicate that the developed design methodology requires substantially less number of CFD simulations compared to using only CFD for the design.

\subsection{Application to Internal Flows}

Propulsion systems of various ongoing and future missile projects are being designed and analyzed through numerical simulation of turbulent reacting flows. 3-D RANS equations are solved alongwith two-equation turbulence model and fast chemistry-based combustion models using commercial software. Liquid fuel is considered as dispersed phase fluid and is modelled through Lagrangian tracking method. Notable internal flow studies include scramjet combustor flow field simulation, Jet vane flow field simulations, air intake characteristics estimation, exhaust plume-free stream interaction at high altitude at base region, conjugate heat transfer studies, starting process in the nozzles and diffusers, analysis of plume ducting system, etc. Few of these internal simulations have been presented.

\subsubsection{Simulation of Scramjet Combustor Flow Field}

Scramjet propulsion system is the preferred choice for hypersonic air-breathing cruise vehicle. CFD is complementing difficult to perform experiments, and playing

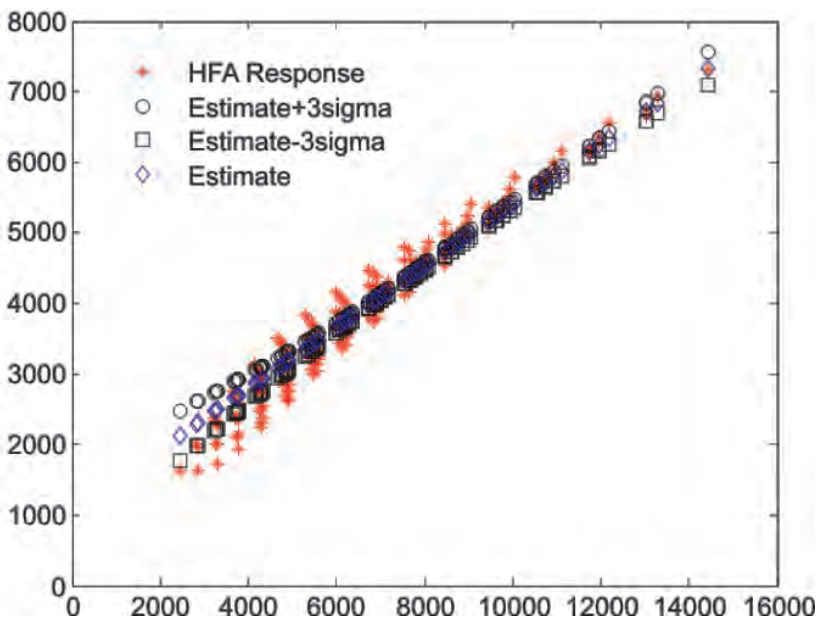

Figure 24. Comparison of predictions from uncertainty model with CFD responses. a major role in the design and analysis activities of the scramjet combustor. Starting from an initial design, the performance of the combustor was improved progressively by relocating the struts and injection locations through analysis of various computed thermochemical parameters in the combustor. Typical Mach number and carbon dioxide distributions at different axial locations are presented in Fig. 25. A comparison of top wall surface pressure for reacting cases is presented in Fig. 26. A very good match is obtained between the experimental and the computational results. The fast chemistry assumption in computation causes instantaneous heat release and is responsible for higher initial peak compared to the experimental value.

\subsubsection{Simulation of Jet Vane Flow Field}

At the initial stage of missile launching, when the speed is not large, the control and stability requirements of the missiles are met by jet vane thrust vector control (TVC) system. The system is operated with small torque, installed in small space and controls pitch, roll, and yaw simultaneously. Simulations were carried out with different
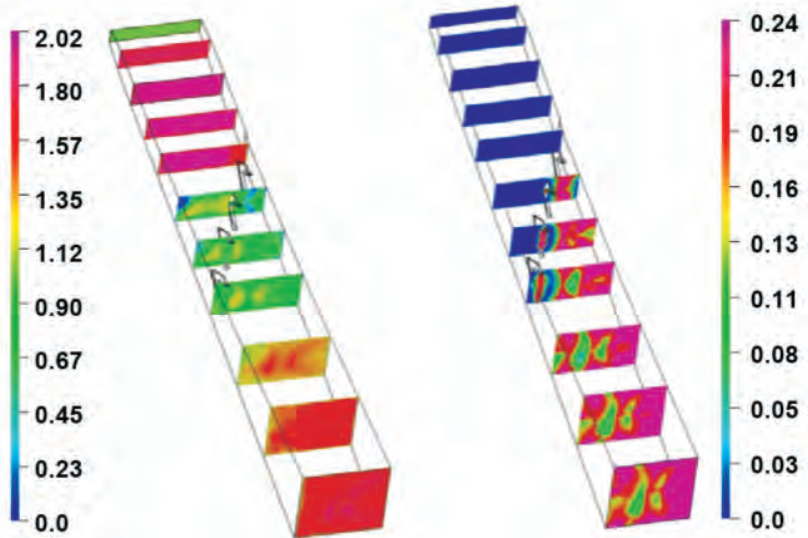

Figure 25. Flow parameters at various axial locations: (a) Mach number, and (b) $\mathrm{CO}_{2}$ mass fraction.

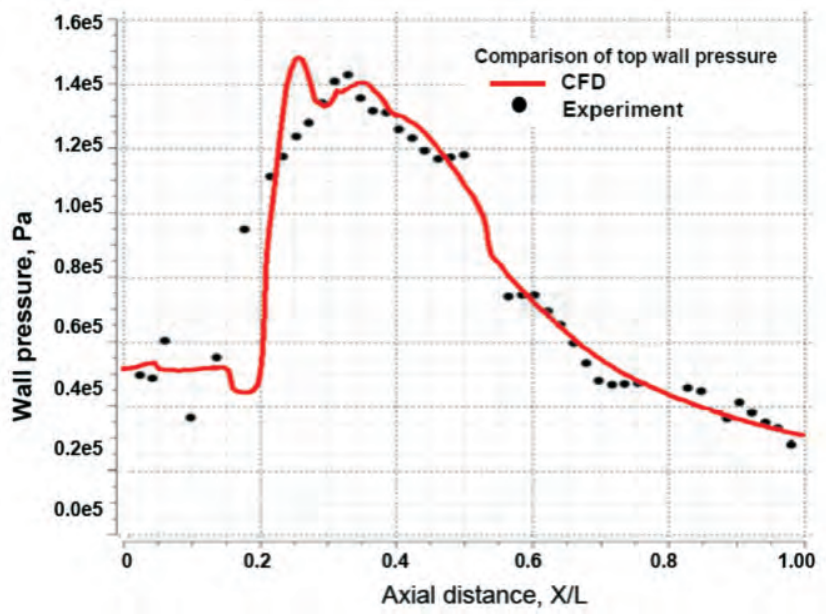

Figure 26. Comparison of Computational and experimental wall pressures for reacting flows. 


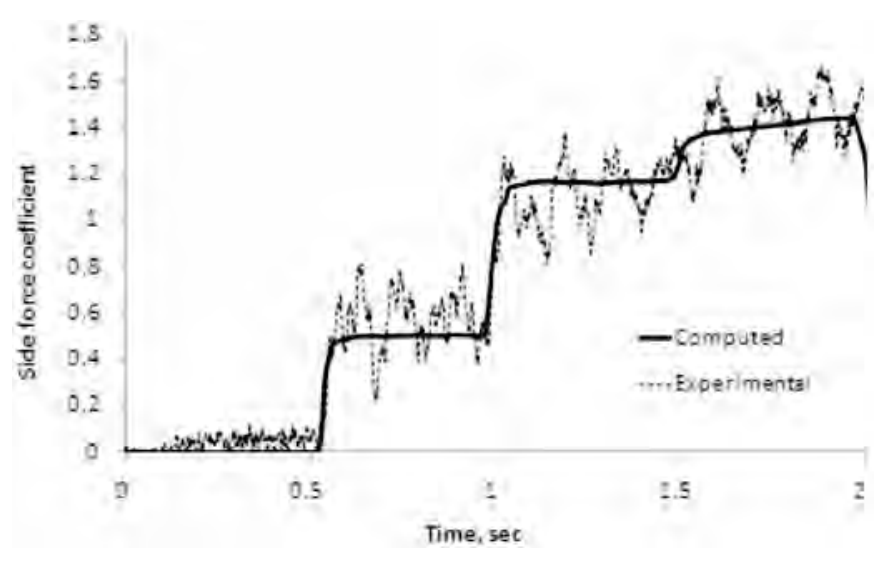

Figure 27.Comparison between correlation and experimental data for side force coefficient.

deflections of opposite vanes for different duty cycle combinations in the presence of hot rocket exhaust. A theoretical correlation ${ }^{24}$ based on CFD database has been developed to predict the vane characteristics (side force and rolling moment) for a given chamber pressure and vane deflection angle. Non-dimensionalised yaw force coefficients calculated from the correlation were compared with experimental results, as shown in Fig. 27. A good comparison of the predicted and experimental values is obtained. The theoretical correlation is utilised in the onboard computer to generate necessary side/roll forces on the aerospace vehicle.

\section{CONCLUSIONS}

Advancements in numerical algorithms, computer hardware, and geometric preprocessing have enabled CFD to simulate the flow field around aerospace vehicles with all its geometrical complexities. This matured technology is not only explaining the complex flow physics, but also providing important design inputs for various aerospace vehicle including fighter and transport aircraft, launch vehicles and missiles. The simulation of these complex aeropropulsive flows requires enormous computing time and memory. To meet the increasing demands from the designers (one run per day), all the computer codes are parallelised and a number of high performance computing platforms based on multi-node cluster computing have been established. CFD has emerged as an important tool in the design and analysis activities of various aerospace vehicles in India and contributing to a faster, accurate, and less expensive design process.

\section{ACKNOWLEDGEMENTS}

CFD works carried out by the scientists of ADA, NAL, VSSC and DRDL are presented. The authors are thankful to all the CFD scientists of these laboratories for readily sharing their works for the paper. The examples presented here are by no way exhaustive. Due to page limitation, some of the important CFD contributions could not be included in the article; our sincere apology for the omission.

\section{REFERENCES}

1. Prahlad, T. S. Status of CFD in India. In Proceedings of $14^{\text {th }}$ International Conference on Numerical Methods in Fluid Dynamics, Bengaluru, 11-15 July 1994. pp. 39-53.

2. Desai, S. S. Relative roles of computational fluid dynamics and wind tunnel testing in the development of aircraft. Current Science, 2003, 84(1), 49-64.

3. Chakrabartty, S. K. Role of computational fluid dynamics in the design of aerospace configurations. J. Aero. Sci. Technol., 2005, 57(1), 24-32.

4. Singh, K.P. CFD tools as applied to Indian combat aircraft configuration - an experience. J. Aero. Sci. Technol., 2005, 57(1), 33-40.

5. Sinha, P.K.; Krishnamurthy, R. \& Chakraborty, Debasis. CFD in aero propulsive design of missiles. In Proceedings of $7^{\text {th }}$ Asian Computational Fluid Dynamics Conference (ACFD-7), Bengaluru, 26-30 November 2007. pp. 6883.

6. Shevare, G. R. Assessment of CFD work in India, science, technologies and industry practice in aerodynamics and design. In Proceedings of SAROD-2009, Bengaluru, 10-12 December 2009. pp. 14-20.

7. Singh, K. P.; Krishna, K Murali; Saha, S. \& Mukherjee,S. $\mathrm{K}$. Application of an Euler code on a modern combat aircraft configuration. In Proceeding of $14^{\text {th }}$ International Conference on Numerical Method in Fluid Dynamics, Bengaluru, 11-15 July 1994. pp. 535-39.

8. Ashok, V.; Kumar, Pradeep; Babu, Thomas \& Devasia, C.K.J. User's manual of PARAS3DVSSC/ARD/TR/033/ 2000-2000.

9. Prakash, Satya. A compressible Navier- Stokes Solver. Report No. ADA/TD/CFD/TR/115, 2003.

10. Chakrabartty, S.K.; Mathur, J.S. \& Dhanalakshmi, K. Application of advanced CFD codes for aircraft design and development at NAL. J. Aero. Sci. Technol., 2003, 55(1), 74-88.

11. Mathur, J.S.;Dhanalakshmi, K. \& Chakrabartty, S.K. Application of advanced CFD codes for design and development of SARAS aircraft. J. Aero. Sci. Technol., 2003, 55(3), 174-85.

12. Nair, Manoj T.; Rampurawala, Abdul M. \& Saxena, S.K. MB-EURANIUM: User's manual, project document CF 0110, National Aerospace Laboratories, Bengaluru, 2001.

13. Padmanabhan, M. A.; Sharanappa, V.; Sajjan, G.; Sen Gupta, V.; Mudkavi, Y. \& Kamesh, J. V. Unsteady RANS- based impulse response studies of NACA 64A010 airfoil for aeroelastic and flutter analysis. In Proc. SAROD-2009, Bengaluru, 10-12 Dec. 2009. pp. 242-50.

14. Chakrabartty, S.K., Dhanalakshmi, K and Ramesh, V. Navier Stokes analysis of GA(W)-2 Aerofoil with deflected flap and resdesign of HANSA flap for better performance. Comp. Fluid Dyn. J., 2003, 12(1), 89-97.

15. Nair, Manoj T.; Kumar, Naresh \& Saxena, S.K. Analysis of inlet aerodynamics for a hypersonic research vehicle. 
J. Prop. Power, 2005, 21(2), 286-91.

16. Unnikrishnan. $C \&$ Balu. R. Development of an unsteady Navier-Stokes solver for aerospace applications. Report No. VSSC/ARD/TR/355/95.

17. Thomas, Tina \& Unnikrishnan, C. CFD studies for wing-elevon gap region of a hypersonic reusable vehicle. In Proceedings of $11^{\text {th }}$ AeSI, Annual CFD symposium, Indian Institute of Science, Bengaluru, August 11-12 2009.

18. Singh, Amit Kumar \& Das, Dipankar. Computational studies on the effect of blockage on starting/unstarting of a hypersonic air intake. In Proceedings of SAROD2009, Bengaluru, India, December 2009. pp. 711-23.

19. Jayachandran, T. Simulation of turbulent reacting twophase flows in propulsion systems. In Proceedings of International Workshop on Turbulent Reacting flows, IIT Madras, Chennai, 19-20 Dec 2002. pp. 135-52.

20. Krishnamurthy, R.; Anandhanarayanan, K. \& Nagarathinam, M. Elliptic grid generation around flight vehicle configurations. In Proc. $4^{\text {th }}$ ECCOMAS Conference, Athens, Greece, 7-11 Sep. 1998. pp. 8-13.

21. Krishnamurthy, R. Kinetic flux vector splitting scheme for unsteady Euler equations on moving grids (KFMG). Aerospace Engineering Department, Indian Institute of Science, Bengaluru. 2002. PhD Thesis.

22. Balasubraminan, R.; Anandhanarayanan, K. \& Balakrishnan, N. Development of a 3-D compressible Reynolds averaged Navier-Stokes solver. In ECCOMAS2004, Jyvaskyla, Finland, July 2004.

23. Umakant, J.; Sudhakar, K.; Mujumdar, P.M. \& Rao, C Raghavendra. Ranking-based model-form uncertainty quantification for a multifidelity design approach. Journal of Aircraft, 2007, 44(2), 410-19.

24. Murty, M.S.R. Chandra; Rao, M. Sambasiva \& Chakraborty, Debasis. Numerical simulation of nozzle flow field with jet vane thrust vector control. J. Aero. Engg., 2010, 224(5), 541-48.

\section{Contributors}

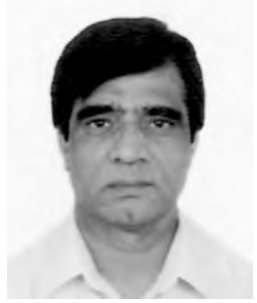

Dr K.P. Singh obtained his $\mathrm{PhD}$ in Aerospace Engineering from Indian Institute of Science(IISc), Bengaluru. $\mathrm{He}$ is currently working as Technical Adviser at Aeronautical Development Agency (ADA), Bengaluru .He superannuated from ADA as a Project Director on 31st December, 2009. He was responsible for aerodynamic activities for Tejas fighter aircraft and its Trainer/ Navy variants, which included CFD. aerodynamics refinements, store-separation studies, flow- field data for air data sensor. wind tunnel testing, and support to flight testing.

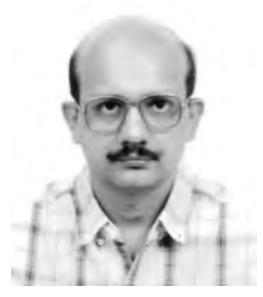

Dr J.S. Mathur is Scientist ' $F$ ' and Joint Head of the Computational and Theoretical Fluid Dynamics Division (TFDD), National Aerospace Laboratories (NAL), Bengaluru. He has a BTech (Aeronautical Engineering) from IIT Kanpur, MS (Aerospace Engineering) from Cornell University, USA, and $\mathrm{PhD}$ (Aerospace Engineering) from IISc Bengaluru. He was a Research Scientist in the University of Wales, Swansea, UK during 1990-91 and 2001-02. His areas of interest are computational fluid dynamics and grid generation for aerospace applications.

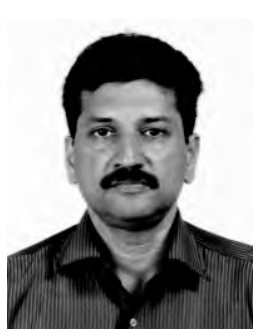

Mr V. Ashok obtained BTech (Mechanical Engineering) from the College of Engineering, Thiruvananthapuram, in 1987. He obtained his MTech (Aerospace Engineering) from IIT Kanpur in 1989. He joined the Vikram Sarabhai Space Centre in 1989 and has been working in the Aerodynamics Division since then. His main interests are in the development and application of CFD codes to aerospace problems. He is the recipient of the Swarna Jayanthi award of the Aeronautical Society of India for 2003.

Dr Debasis Chakraborty (see page no. 576) 